Original Article

\title{
IN VITRO FREE RADICAL SCAVENGING ACTIVITY OF BAUHINIA RACEM OSA
}

\author{
Bhagya Bhaskar', Ramakrishna Avadhani \\ ${ }^{1}$ Lecturer, Department of Anatomy, Yenepoya Medical College, Yenepoya University, India. \\ ${ }^{2}$ Professor, Department of Anatomy, Yenepoya M edical College, Yenepoya University, India. \\ Correspondence : \\ Ramakrishna Avadhani \\ Professor, Department of Anatomy, Yenepoya Medical College, Yenepoya University, Deralakatte, \\ University Road, M angalore - 575018. \\ Ph: 0824 2204668/69/70 E-mail : bagyabs@gmail.com
}

\begin{abstract}
:
In vitro free radical scavenging activity of aqueous and ethanolic bark extracts of Bauhinia racemosa was assessed by studying its ability to scavenge DPPH, Nitric oxide, hydroxyl radical and reducing power. Both the extracts showed effective free radical scavenging activity. Ethanolic extract was comparatively more potential than aqueous extract. The results support its traditional use in various ailments and as a source of natural antioxidants which protect cells against oxidative stress.
\end{abstract}

Keywords: Bauhinia racemosa, Phytochemicals, DPPH, Nitric oxide, hydroxyl radical, reducing power

\section{Introduction :}

Reactive Oxygen species (ROS) the byproducts of biological reactions are known to induce oxidation of lipids, damage cell membranes and cause DNA mutation ${ }^{1}$. ROS are also reported to be causative in development of degenerative diseases, such as cancer ${ }^{2}$, cardiovascular diseases ${ }^{3}$, neural degeneration ${ }^{4}$, diabetes and obesity ${ }^{5}$. Antioxidant action involves suppressing the formation of ROS, scavenging the free radicals, reducing agents and quenchers of singlet oxygen formation ${ }^{6}$.

Bauhinia racemosa Lam belongs to the family Caesalpiniaceae, is widely distributed throughout India. Different parts of the plant are used traditionally in treatment of various ailments. The stem bark is extensively used as an astringent and in the treatment of headache, fever, inflammation, skin diseases, tumors, blood diseases, dysentery and diarrhea ? Access this article online Quick Response Code
Exploring active pharmacological compounds in plants traditionally used as medicine is gaining interest. Natural antioxidants such as plant polyphenols play an important role in inhibiting and scavenging free radicals ${ }^{8}$. From this viewpoint the present study was carried out to evaluate the in vitro free radical scavenging activity of aqueous and ethanolic bark extracts of $B$. racemosa.

\section{Materials and Methods \\ Collection and Identification of plant materials}

The bark of B. racemosa L. was collected in the month of November 2011, from Yenepoya University campus, Mangalore, Karnataka, India. The plant material was taxonomically identified by a botanist. The fresh bark collected were washed with distilled water to remove dust and was shade dried, pulverized by a mechanical grinder and stored in airtight containers for further use.

\section{Preparation of extracts}

Aqueous and ethanolic extracts of B. racemosa bark were prepared as per the guidelines of Raaman ${ }^{9}$. The extracts were prepared by maceration technique. The bark powder $(10 \mathrm{~g})$ was extracted with ethanol $(150 \mathrm{ml})$ and the solution was concentrated in a water bath at $60^{\circ} \mathrm{C}$ to obtain a brownish black ethanolic extract (EBR - ethonalic extract Bauhinia racemosa). About $30 \mathrm{~g}$ of the bark powder was dissolved in $200 \mathrm{ml}$ of distilled water. The solution was concentrated under reduced pressure by lyophilizer 
(OPERON-FDB-5003) to yield the aqueous extract (ABR aqueous extract Bauhinia racemosa). The yield of the extracts was noted and was kept in a refrigerator until further use.

\section{Phytochemical analysis}

Preliminary phytochemical tests are used to detect the presence of various organic functional groups, which is the indicative of type of phytochemicals present in the plant. These tests indicate the presence of different class of constituents present in the extract. Tests were performed as per the methodology mentioned by Harborne ${ }^{10}$.

Tests for Alkaloids

a. Dragendroff's test: To a few mg of extract dissolved in alcohol, a few drops of acetic acid and Dragendroff's reagent were added and shaken well. An orange red precipitate formed indicates the presence of alkaloids.

b. Wagners's tests: To a few mg of extract dissolved in acetic acid, a few drops of Wagner's reagent was added. A reddish brown precipitate formed indicates the presence of alkaloids.

c. Mayer's test: To a few mg of extract dissolved in acetic acid, a few drops of M ayer's reagent was added. A dull white precipitate formed indicates the presence of alkaloids.

d. Hager's test: To a few mg of extract dissolved in acetic acid, $3 \mathrm{ml}$ of Hager's reagent was added, the formation of yellow precipitate indicates the presence of alkaloids.

\section{Test for Carbohydrates}

a. Molisch's test: To the extract, $1 \mathrm{ml}$ of -naphthol solution and conc. sulphuric acid were added along the sides of the test tube. Violet colour formed at the junction of the two liquids indicates the presence of carbohydrates.

b. Fehling's test: A few mg of extract was mixed with equal quantities of Fehling's solution A and B. The mixture was warmed on a water bath. The formation of a brick precipitate indicates the presence of carbohydrates.

c. Anthrone-sulphuric acid test: A few mg of the extract was mixed with equal quantity of anthrone and treated with two drops of conc. sulphuric acid. It was then heated gently on a water bath. Dark green colour formed indicates the presence of sugar/glycoside.

\section{Test for Steroids}

a. Libermann-Burchard test: To the extract was dissolved in chloroform, $1 \mathrm{ml}$ of acetic acid and $1 \mathrm{ml}$ of acetic anhydride were added, then heated on a water bath and cooled. Few drops of conc. sulphuric acid was added along the sides of the test tube. Appearance of bluish green colour indicates the presence of steroids.

b. Salkowski test: The extract was dissolved in chloroform and equal volume of conc. sulphuric acid was added. Formation of bluish red to cherry red colour in chloroform layer and green fluorescence in the acid layer indicates the presence of steroids.

\section{Test for Saponins}

a. To a few mg of extract, distilled water was added and shaken. Stable froth formation indicates the presence of saponins.

\section{Testfor Tannins}

a. To the extract, a few drops of dilute solution of ferric chloride was added, formation of dark blue colour shows the presence of tannins.

\section{Test for flavonoids}

a. Shinoda's test: To the extract in alcohol, a few magnesium turnings and few drops of conc. Hydrochloric acid were added and heated on a water bath. Formation of red to pink colour indicates the presence of flavonoids.

\section{Test for Phenols}

a. To the extract in alcohol, added two drops of alcoholic ferric chloride. Formation of blue to blue black indicates the presence of phenol.

\section{Test for Coumarins}

a. To the extract in alcohol, a few drops of $2 \mathrm{~N}$ sodium hydroxide solution was added. Dark yellow colour formation indicates the presence of coumarins.

\section{Test for Triterpenoids}

a. The extract was warmed with tin bits and few drops of 
thionyl chloride. Formation of pink colour indicates the presence of triterpenoids.

\section{Test for Carboxylic acid}

a. Extract dissolved in water is treated with sodium bicarbonate. Brisk effervescence indicates the presence of carboxylic acid.

\section{Antioxidant Activity}

1, 1-Diphenyl-2-picryl-hydrazyl (DPPH) was obtained from Sigma Aldrich Co., St. Louis, USA. All other chemicals used were of analytical grade.

DPPH-radical scavenging activity

DPPH-radical scavenging activity was determined according to the technique outlined by George ${ }^{11}$. A $0.002 \%$ of DPPH in methanol was prepared and $1 \mathrm{ml}$ of this solution was added to $1 \mathrm{ml}$ of different concentrations of extracts $(10 \mu \mathrm{g} / \mathrm{ml}$ to $100 \mu \mathrm{g} / \mathrm{ml}$ and standard (Ascorbic acid), allowed to stand for $30 \mathrm{~min}$ at room temperature. All tests were performed in triplicate. The change in color from purple to yellow was measured at $517 \mathrm{~nm}$ in a spectrophotometer (SYSTRONICS 2201). M ethanol with extract served as the blank and DPPH in methanol without the extracts served as the positive control. The percentage of radical scavenging activity was calculated using the following formula:

$\%$ Antioxidant scavengingactivity $=\left[\left(A_{0}-A_{1}\right) / A_{0}\right] \times 100$

Where, $A_{0}=$ Absorbance of control. $A_{1}=$ Absorbance of sample

Nitric oxide radical scavenging assay

Free radical scavenging activity by nitric oxide scavenging test was assessed by the Griess-liosvay reaction proposed by Garret ${ }^{12} .2 \mathrm{ml}$ of Sodium nitroprusside $(10 \mu \mathrm{M})$ in $0.5 \mathrm{ml}$ of standard phosphate buffer solution was incubated with $0.5 \mathrm{ml}$ of different concentration of the test extracts (10 $\mu \mathrm{g} / \mathrm{ml}-100 \mu \mathrm{g} / \mathrm{ml}$ ) dissolved in standard phosphate buffer $(0.025 \mathrm{M}, \mathrm{pH} 7.4)$ and the tubes were incubated at $25^{\circ} \mathrm{C}$ for $21 / 2 \mathrm{hr}$. To $0.5 \mathrm{ml}$ of incubated mixture $1 \mathrm{ml}$ of $0.33 \%$ sulfanilic acid was added and allowed to stand at room temperature for $5 \mathrm{~min}$. After incubation $1 \mathrm{ml}$ of $0.1 \%$ of naphthyl ethylenediamide dichloride was added, mixed the content and incubated at room temperature for 30 minutes. All tests were performed in triplicate. The absorbance of the mixture at $540 \mathrm{~nm}$ was measured with a Double beam UV-visible Spectrophotometer (SYSTRONICS 2201). Distilled water served as the blank. Nitric oxide radical scavenging activity was calculated according to the following formula:

$$
\% \text { inhibition }=\left[\left(A_{0}-A_{1}\right) / A_{0}\right] \times 100
$$

Where, $A_{0}=$ Absorbance of control. $A_{1=}$ Absorbance of sample

The activity was compared with ascorbic acid, which was used as a standard antioxidant.

\section{Reducing power assay}

The reducing power of the extracts was assessed by the method proposed by Oyaizu ${ }^{13}$. A $0.75 \mathrm{ml}$ of various concentrations of the extracts $(10 \mu \mathrm{g} / \mathrm{ml}-100 \mu \mathrm{g} / \mathrm{ml})$ was mixed with $0.75 \mathrm{ml}$ of phosphate buffer $(0.2 \mathrm{M} \mathrm{pH} \mathrm{6.6)} \mathrm{and}$ $0.75 \mathrm{ml}$ of potassium ferricyanide ( $1 \% \mathrm{v} / \mathrm{v}$ ). Incubated at 50 ${ }^{\circ} \mathrm{C}$ for $20 \mathrm{~min}$. The reaction was stopped by adding $0.75 \mathrm{ml}$ of $10 \%$ trichloroacetic acid, centrifuged at $800 \mathrm{rpm}$ for 10 minutes. $1.5 \mathrm{ml}$ of supernatant was mixed with $1.5 \mathrm{ml}$ distilled water and $0.1 \mathrm{ml}$ ferric chloride (0.1\%). Incubated at room temperature for 10 minutes and the absorbance at $700 \mathrm{~nm}$ were measured with Double beam UV-visible Spectrophotometer (SYSTRONICS 2201). All tests were performed in triplicate. Higher absorbance of reaction mixture indicates the greater reducing power as compared to ascorbic acid (Standard). The percentage of radical scavenging activity was calculated using the following formula:

$\%$ Antioxidant scavenging activity $=\left[\left(A_{0}-A_{1}\right) / A_{0}\right] \times 100$ Where, $A_{0}=$ Absorbance of control. $A_{1=}$ Absorbance of sample

Hydroxyl radical scavenging activity

The scavenging activity for hydroxyl activity was assayed according to the method of $\mathrm{Yu}^{14}$. About $60 \mu \mathrm{l}$ of ferrous chloride ( $1 \mathrm{mM}$ ), was added to $90 \mu$ l of 1,10 phenanthroline 
(1mM ). About $2.4 \mathrm{ml}$ of phosphate buffer saline $(0.2 \mathrm{M}, \mathrm{pH}$ 7.4) was added to the mixture, followed by the addition of $150 \mu \mathrm{l}$ of hydrogen peroxide $(0.17 \mathrm{M})$ and $1.5 \mathrm{ml}$ of different concentrations of the extracts $(10 \mu \mathrm{g} / \mathrm{ml}$ $100 \mu \mathrm{g} / \mathrm{ml}$ ). The mixture was incubated for $5 \mathrm{~min}$ at room temperature. All tests were performed in triplicate. The absorbance of the mixture was read at $560 \mathrm{~nm}$ in a Double beam UV-visible Spectrophotometer (SYSTRONICS 2201) against blank (distilled water). The hydroxyl radical scavenging activity was calculated according to the following formula.

$$
\% \text { inhibition }=\left[\left(A_{0}-A_{1}\right) / A_{0}\right] \times 100
$$

Where, $A_{0}=$ Absorbance of control. $A_{1=}$ Absorbance of sample

\section{Statistical Analysis :}

The data obtained have been presented as M ean \pm SEM . The difference between the control group and test extracts treated group was analyzed by employing one way ANOVA (Analysis of Variance) followed by Dunnett's multiple ' $\mathrm{t}$ ' test as post hoc test. A $p \varangle 0.05$ was considered as statistically significant.

\section{Results:}

Aqueous extract of B. racemosa yielded $12 \%$ and ethanolic extract was $0.8 \%$ respectively. These extracts were subjected for preliminary phytochemical screening and antioxidant analysis.

\section{Phytochemicals}

The results of preliminary phytochemical study are tabulated in Table I. The results revealed the presence of pharmacologically active chemical compounds such as steroid, phenol/ tannin, glycoside/ sugar, carbohydrate and terpenoids in both the extracts.

\section{DPPH scavenging activity}

The percentage of DPPH radical scavenging activity of Bauhinia extracts is presented in Figure 1. EBR has got very good scavenging activity. The effect is found to be dose dependant. Higher dose has showed higher activity compared to the other doses. ABR shows presence of very good free radical scavenging activity in DPPH assay. The effect was statistically highly significant in all the doses tested in comparison to control group. It was also found to be dose dependent up to the dose of $80 \mu \mathrm{g} / \mathrm{ml}$ there after it exhibited saturation of the effect.

\section{Nitric oxide scavenging activity}

Figure 2 shows the measure of nitric oxide scavenging activity of Bauhinia aqueous and ethanolic extracts. EBR has showed dose independent activity. Lower dose and higher dose (i.e. $80 \mu \mathrm{g} / \mathrm{ml}$ ) has showed good scavenging activity compared to other dosage levels. The difference between the control group and test drug group was found to be highly significant with respect to all the doses $(p<0.01$ ) except $60 \mu \mathrm{g} / \mathrm{ml}$ group in which the difference was found to be statistically just significant $(p \varangle 0.05)$. In ABR, effect is found to be independent of dosage levels. Three different dosage levels i.e., 20, 60 and $100 \mu \mathrm{g} / \mathrm{ml}$ has produced similar effect, where as the lower concentration found to be highly effective compared to the other dosage levels. ABR produced moderate but statistically significant nitric oxide scavenging effect at the dose of $10 \mu \mathrm{g} / \mathrm{ml}$. However, with the higher doses the activity was marginal and statistically non-significant.

\section{Hydroxyl radical scavenging activity}

Antioxidant activity of aqueous and ethanolic Bauhinia bark extracts by hydroxyl radical scavenging activity is presented in Figure 3. EBR exhibited weak hydroxyl radical scavenging activity which was not dose dependent. The inhibition observed was found to be statistically nonsignificant with respect to the inhibition observed at all the dose levels tested. ABR has moderate but statistically nonsignificant hydroxyl radical scavenging effect up to the dose of $60 \mu \mathrm{g} / \mathrm{ml}$ in comparison to control set. The activity was found to decrease at higher dose levels.

\section{Reducing power assay}

The capacity of Bauhinia extracts to reduce $\mathrm{Fe}^{3+}$ to $\mathrm{Fe}^{2+}$ is shown in Figure 4. EBR exhibited good reducing power activity at lower dose level ( 10 and $20 \mu \mathrm{g} / \mathrm{ml} ; \mathrm{P}<0.01$ and 0.05 respectively). The reducing activity was found to be moderate to weak and statistically non-significant at higher dose level in comparison to control set of tubes. ABR 


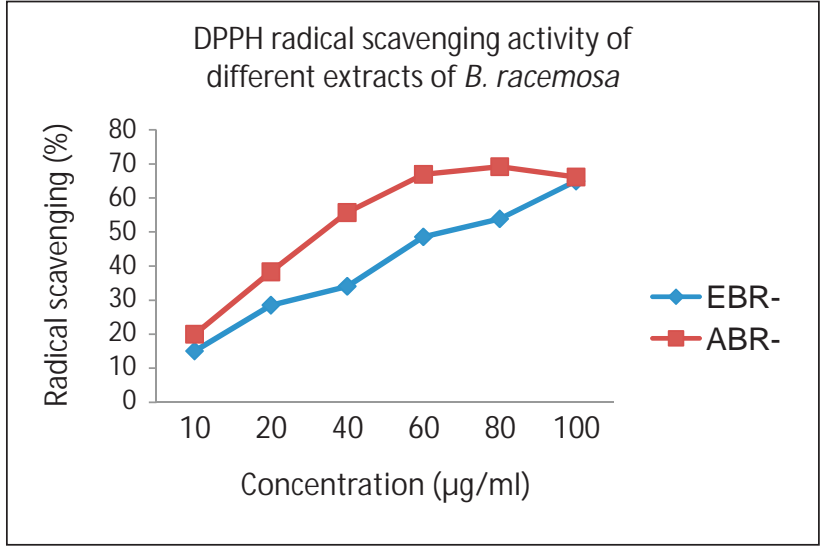

Fig 1: DPPH radical scavenging activity of aqueous and ethanolic extracts of B. racemosa

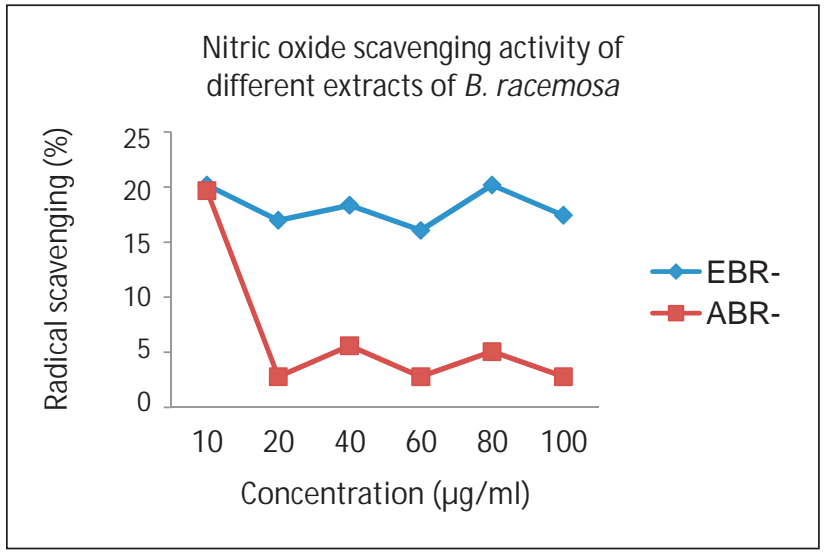

Fig 2: Nitric oxide scavenging activity of aqueous and ethanolic extracts of $\mathrm{B}$. racemosa

Table I- Results for preliminary phytochemical tests of different extracts of Bauhinia racemosa

\begin{tabular}{|l|c|c|}
\hline TEST & EBR & ABR \\
\hline Alkaloid & - & - \\
\hline Coumarin & - & - \\
\hline Flavone & - & - \\
\hline Carbohydrate & + & + \\
\hline Steroid & + & + \\
\hline Phenol & + & + \\
\hline Tannin & + & + \\
\hline Glycoside/sugar & + & + \\
\hline Terpenoid & + & + \\
\hline Carboxylic acid & - & - \\
\hline Saponins & - & - \\
\hline
\end{tabular}

EBR - ethonalic extract Bauhinia racemosa; $A B R$ - aqueous extract Bauhinia racemosa

produced a moderate but inconsistent and dose independent reducing effect which was found to be statistically non-significant.

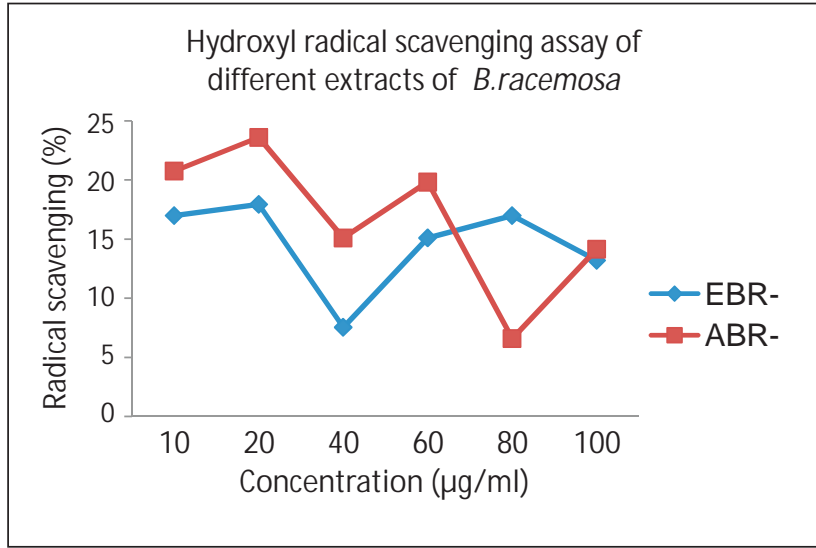

Fig 3: Hydroxyl radical scavenging activity of aqueous and ethanolic extracts of B. racemosa

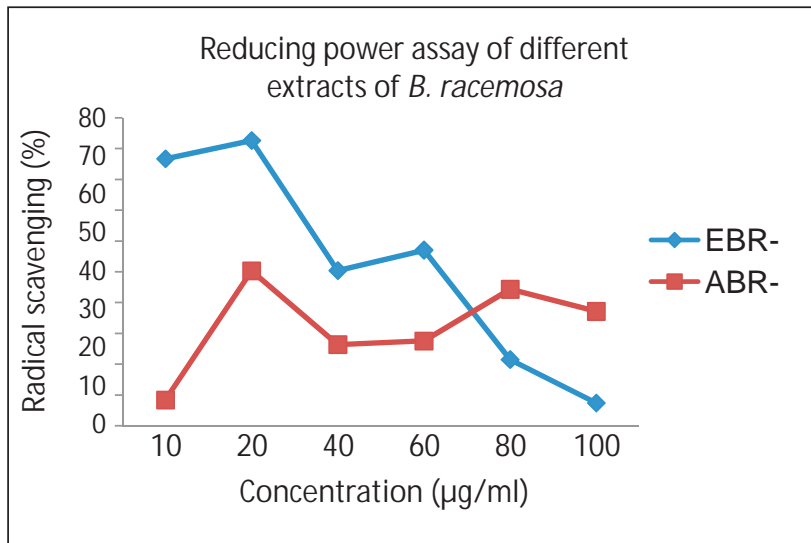

Fig 4: Reducing power assay of aqueous and ethanolic extracts of $\mathrm{B}$. racemosa

\section{Discussion:}

Phenolic compounds are reported to possess antioxidant activity because their hydroxyl groups have considerable scavenging capacity ${ }^{15}$. Analysis of the results indicates presence of good free radical scavenging activity against both ROS (Reactive Oxygen Species) and RNS (Reactive Nitrogen Species) generation in Bauhinia racemosa aqueous and ethanolic bark extracts. It also has good reducing effect which may be the basis for the observed free radical scavenging activity. These antioxidant scavenging in vitro assays indicate that EBR has got better free radical scavenging potential in comparison to ABR. The present study supports the in vitro antioxidant potential of B. racemosa which by further in vivo studies are necessary to confirm and extend these results.

\section{Acknowledgement:}

The authors are grateful to Yenepoya University for permission to carry out this study. 


\section{References:}

1. Cerutti P: Oxy-radicals and cancer. Lancet 1994; 344:862-863.

2. Hertog MGL, Bueno de Mesquita HB, Fehily AM, Sweetnam PM Elwood PC, Kromhout D: Fruit and vegetable consumption and cancer mortality in the caerphilly study. Cancer Epidemiol Biomarkers Prev 1996; 5: 673-677.

3. Vita JA: Polyphenols and cardiovascular disease: Effects on endothelial and platelet function. Am J Clin Nutr 2005; 81: 292-297.

4. Youdim KA, Spencer JPE, Schroeter H, Rice-Evans CA: Dietary flavonoids as potential neuroprotectans. J Biol Chem 2002; 383: 503 519.

5. Tsuda T, Horio F, Uchida K, Aoki H, Osawa T: Dietary cyaniding 3-0-b Dglucoside-rich purple corn colour prevents obesity and ameliorates hyperglycemia in mice. J Nutr 2003; 133: 2125-2130.

6. Andlauer W, Furst P: Antioxidative power of phytochemicals with special reference to cereals. Cereal Foods World 1998; 43: 356-359.

7. Kirtikar KR, Basu BD: Indian medicinal plants. Bishen Mahendra Pal Singh, Second edition, Dehradun, India 1975; 2: 842-844.

8. Rice-Evans CA: Flavonoid antioxidants. Curr M ed Chem 2001; 8: 797 807.
9. Raaman N: Phytochemical Techniques. New India Publishing Agency, New Delhi 2006; 9-18.

10. Harborne JB: Phytochemical M ethods. Jackman H. (Ed.), London 1973; 70.

11. George B, Kaur C, Khurdiya DS, Kapoor HC: Antioxidants in tomato (Lycopersium esculentum) as a function of genotype. Food Chem 2004: 84: 45-51.

12. Garret DC: The Quantitative analysis of Drugs, Chapman and Hall Ltd. Japan 1964; 3:456-458

13. Oyaizu M: Studies on product of browning reaction prepared from glucose amine. Japanese Journal of Nutrition 1986; 44: 307-15.

14. Yu W, Zhao Y, Shu B: The radical scavenging activities of Radix purariae isoflavanoids: A chemiluminescence study. Food Chemistry 2004; 86: $525-29$.

15. Hazra B, Biswas S, M andal N: Antioxidant and free radical scavenging activity of Spondias spinnate. BM C Complementary and alternative medicine 2008; 8: 63-72 